\title{
AN OUTLOOK FOR RADICAL AERO ENGINE INTERCOOLER CONCEPTS
}

\author{
Olivier Petit ${ }^{1}$, Carlos Xisto ${ }^{2}$, Xin Zhao ${ }^{3}$, Tomas Grönstedt ${ }^{4}$ \\ Chalmers University of Technology \\ Applied Mechanics \\ Gothenburg, Sweden
}

\section{ABSTRACT}

A state of the art turbofan engine has an overall efficiency of about $40 \%$, typically composed of a 50\% thermal and an $80 \%$ propulsive efficiency. Previous studies have estimated that intercooling may improve fuel burn on such an engine with a 3$5 \%$ reduction depending on mission length. The intercooled engine benefits stem firstly from a higher Overall Pressure Ratio $(O P R)$ and secondly from a reduced cooling flow need. Both aspects relate to the reduced compressor exit temperature achieved by the intercooler action. A critical aspect of making the intercooler work efficiently is the use of a variable intercooler exhaust nozzle. This allows reducing the heat extracted from the core in cruise operation as well as reducing the irreversibility generated on the intercooler external surface which arises from bypass flow pressure losses. In this respect the improvements, higher OPR and lower cooling flow need, are achieved indirectly and not by directly improving the underlying thermal efficiency.

This paper discusses direct methods to further improve the efficiency of intercooled turbofan engines, either by reducing irreversibility generated in the heat exchanger or by using the rejected heat from the intercooler to generate useful power to the aircraft. The performance improvements by using the nacelle wetted surface to replace the conventional intercooler surface is first estimated. The net fuel burn benefit is estimated at 1.6\%. As a second option a fuel cooled intercooler configuration, operated during the climb phase, is evaluated providing a net fuel burn reduction of $1.3 \%$.

A novel concept that uses the rejected heat to generate additional useful power is then proposed. A secondary cycle able to convert rejected intercooler heat to useful thrust is used to evaluate three possible scenarios. The two first cases investigate the impact of the heat transfer rate on the SFC reduction. As a final consideration the geared intercooled engine cycle is reoptimized to maximize the benefits of the proposed heat recovery system. The maximum SFC improvement for the three cycles is established to $2 \%, 3.7 \%$ and $3 \%$.

$\begin{array}{ll}\text { NOMENCLATURE } \\ C & \text { Absolute velocity } \\ \mathrm{c}_{\mathrm{p}} & \text { Heat capacity at constant pressure } \\ h & \text { Enthalpy } \\ h_{0} & \text { Stagnation enthalpy } \\ K & \text { Constant } \\ \dot{m} & \text { Mass flow rate } \\ p & \text { Pressure } \\ Q & \text { Transferred heat } \\ \dot{Q} & \text { Heat transfer rate } \\ R & \text { Gas constant } \\ S & \text { Specific entropy } \\ T_{C}, T_{L} & \text { Temperature of the cold reservoir } \\ T_{H} & \text { Temperature of the hot reservoir } \\ T & \text { Temperature } \\ \Delta & \text { Change } \\ \varepsilon & \text { Specific exergy content } \\ \eta & \text { Cycle efficiency } \\ \text { BC } & \text { Boundary conditions } \\ \text { BPR } & \text { Bypass ratio } \\ \text { CFD } & \text { Computational Fluid Dynamics } \\ \text { FPR } & \text { Fan pressure ratio } \\ \text { HPC } & \text { High Pressure Compressor } \\ \text { IC } & \text { Intercooled engine } \\ \text { IP } & \text { Intermediate Pressure } \\ \text { IPC } & \text { Intermediate Pressure Compressor } \\ \text { IS } & \text { Inner surface }\end{array}$

\footnotetext{
${ }^{1}$ Assistant professor, olivierp@chalmers.se

${ }^{2}$ Post-doctoral researcher, carlos.xisto@chalmers.se

${ }^{3} \mathrm{Ph} . \mathrm{D}$. student, zxin@ chalmers.se

${ }^{4}$ Professor, tomas.gronstedt@chalmers.se
} 
ISA International standard atmosphere

Ma Mach number

NA Not Available

NTU Number of Transfer Units

OPR Overall pressure ratio

OS Outer surface

\section{INTRODUCTION}

The increasing global mobility demand and its relation to the environmental impact is a major challenge for the future of aviation. The Advisory Council of Aeronautics Research in Europe (ACARE) has thus set targets of reduction of $\mathrm{CO}_{2}$ emissions by $75 \%$ and perceived noise by $65 \%$ to reduce the aviation environmental impact [1]. One possible action for the engine sector to meet the $\mathrm{CO}_{2}$ target specified by ACARE is to improve the thermal efficiency of the engine. Indeed, improving the thermal efficiency reduces the fuel burn and thus the $\mathrm{CO}_{2}$ emissions. The ENOVAL project focuses on the low pressure system of Ultra-High By-Pass Ratio (UHBPR) propulsion systems $(12<$ BPR $<20)$ in conjunction with ultra-high overall pressure ratio $(50<\mathrm{OPR}<70)$ to provide significant reductions in $\mathrm{CO}_{2}$ emissions (26\% reduction in relation to the year 2000 reference) [2]. As a part of this project a number of radical intercooler concepts are being investigated.

Aspects of intercooler integration into advanced cores have been explored previously within the NEWAC project by Rolls Royce Plc and Oxford University [3]. More recent work has illustrated the synergies between intercooling and a geared engine concept $[4,5]$. A low pressure system integration was tested at Loughborough University [6], demonstrating the feasibility of such an installation. The concept comprises a ducting system splitting the air into two streams, an external bypass flow and an internal bypass flow, as illustrated in Figure 1. The internal bypass flow is passed over the intercooler to provide the cooling. The original concept applied a downstream mixer [6]. Later publications have discussed the use of a variable intercooler exhaust nozzle [5, 7].

The fuel burn benefit of intercooling has been assessed to provide up to a 5\% reduction potential [5] on a year 2025 geared intercooled engine, for a mission length of $6800 \mathrm{~km}$ and a twin engine aircraft model. Such benefits are maximized by reducing the amount of irreversibility that the cooler generates in cruise. This is done by closing a variable nozzle thereby cutting down on the intercooler external flow and hence pressure and viscous losses in the bypass flow. It is possible to drive this effect further by also allowing variability of the engine core flow that goes through the intercooler with the mean of a variable flow path [8]. Using such intercooler control measures keep the losses down. At the same time the use of intercooling enables an increased overall pressure ratio and reduces the turbine cooling flow needed, allowing for the estimated benefits.

This paper discusses new approaches to further increase the fuel burn efficiency improvement potential of intercooled turbofan engines. Two types of concepts are studied:

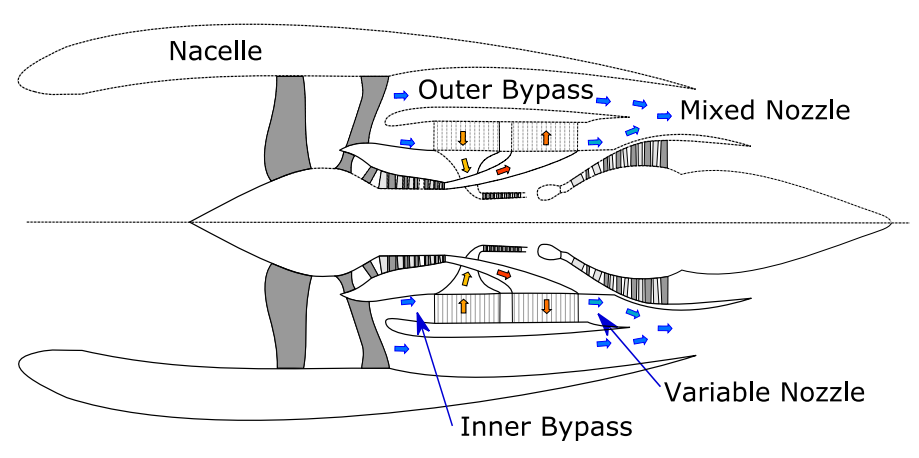

FIGURE 1: INTERCOOLER INSTALLATION OPTIONS.

- Type 1: means to directly reduce the irreversibility generated by the intercooler. In this work heat rejection through the engine nacelle as well by temporarily heating the fuel is considered.

- Type 2: converting the rejected heat into useful power.

In the past, intercooler concepts, like the one illustrated in Figure 1 [7] have rejected heat by creating additional drag in the bypass duct. The nacelle heat rejection system studied herein (a Type 1 concept) evaluates the potential for increased efficiency by using drag surfaces already available in the aircraft. In the paper, it is explained and illustrated by CFD simulations, that the drag on the nacelle can actually be reduced by such a heat rejection system. The high bypass ratio of intercooled engines, estimated to be more than 17 for a year 2025 entry into service engine, makes it possible to fit such a cooling system into the engine maintaining a high proportion of the benefits. For lower bypass ratios such installations would become bulky and it would be necessary to reach high speeds within the nacelle cooler to accommodate the core mass flow.

The intercooler concept that rejects heat to the fuel is designed to operate up to the top-of-climb operating point to keep temperature increase in the fuel below its auto-ignition temperature $\left(211{ }^{\circ} \mathrm{C}\right.$ for Jet A fuel for example). The heat rejection to the fuel is intrinsically more efficient than the nacelle heat rejection concept since the heat is preserved, and re-used in the cycle.

In the past, systems designed to use rejected heat to generate additional useful power have focused on the recovery of heat in the core exhaust [9]. However, heat rejected by intercoolers is an equally feasible option for such a solution providing, as will be discussed, some additional advantages for its installation. As a first work in this area, this paper concentrates on establishing the fuel burn saving potential for such an installation. Upper bounds for improvements are established by including an estimate of loss based on a combined use of previous design experience on organic Rankine cycles and an expression using a semi-empirical Carnot efficiency. The most promising concept is analyzed further by outlining the thermodynamic operating conditions of the cycle and by proposing a suitable working fluid. 


\section{IRREVERSIBILITY AND INTERCOOLING}

Intercooling is an inherently irreversible process both through the losses generated from pressure drop as well as originating from finite temperature difference. These losses influence not only the performance benefits that can be achieved through intercooling but also how intercoolers should best be installed. To provide a basis for discussing intercooling installation, in particular selecting the pressure ratio for installation, some basic analysis tools are now introduced.

The irreversibility, $\Delta \mathrm{s}$, of the thermodynamic process of heat exchange can, in its simplest form be described by:

$$
\Delta s=\frac{Q}{T_{C}}-\frac{Q}{T_{H}}
$$

where $Q$ is the transferred heat, $T_{C}$ is the temperature of the cold reservoir and $T_{H}$ is the temperature of a hot reservoir. This equation is fully applicable only for two reservoirs that are brought into contact for a finite time. Intercoolers, on the other hand, work in a continuous flow basis. Still, equation (1) is sufficiently relevant to include one important behavior; the larger the temperature difference the greater the irreversibility.

Introducing the intercooler at a lower pressure ratio in the cycle will push the hot temperature closer to the temperature in the bypass duct and hence this would potentially increase the thermodynamic efficiency. This will on the other hand require a larger intercooler since the driving temperature is smaller, leading to a bulkier and heavier installation. Such an installation will inevitably lead to larger pressure losses since the flow speed in the available free flow volumes will have to increase.

A more realistic impression of the generated losses is derived from a simplistic heat exchanger model as illustrated in Figure 2. The work potential, i.e. the exergy, per unit mass of a flow stream is [10]:

$\varepsilon=\left(h-h_{\infty}\right)-T_{\infty}\left(s-s_{\infty}\right)+\frac{C^{2}}{2}$

where $\infty$ denotes the equilibrium condition, as defined through the ambient conditions of the environment. Introducing the stagnation enthalpy we get:

$\varepsilon=h_{0}-T_{\infty} s+\underbrace{T_{\infty} s_{\infty}-h_{\infty}}_{\text {Constant }}$

The first law for an open system with no work transfer is written:

$\dot{Q}=\dot{m} \Delta h_{0}$

The net exergy change of the intercooler is:

$$
\begin{aligned}
& \Delta \varepsilon=\Delta \varepsilon_{\text {cold }}+\Delta \varepsilon_{\text {hot }} \\
& \Delta \varepsilon_{\text {cold }}=\dot{m}_{\text {cold }} \Delta h_{0, \text { cold }}-\dot{m}_{\text {cold }} \Delta\left(T_{\infty} s\right)_{\text {cold }}=\dot{Q}-\dot{m}_{\text {cold }} T_{\infty} \Delta s_{\text {cold }} \\
& \Delta \varepsilon_{\text {hot }}=\dot{m}_{\text {hot }} \Delta h_{0, \text { hot }}-\dot{m}_{\text {hot }} \Delta\left(T_{\infty} s\right)_{\text {hot }}=-\dot{Q}-\dot{m}_{\text {hot }} T_{\infty} \Delta s_{\text {hot }}
\end{aligned}
$$

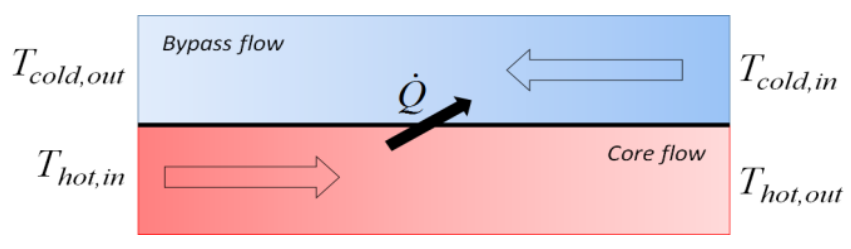

FIGURE 2: SCHEMATIC HEAT EXCHANGER.

The net exergy change can then simply be written:

$$
\Delta \varepsilon=-T_{\infty}\left(\dot{m}_{h o t} \Delta s_{h o t}+\dot{m}_{\text {cold }} \Delta s_{\text {cold }}\right)
$$

Note that this relationship is derived using only the definition of exergy and the first law. It is hence valid for any level of stagnation pressure loss occurring in the two flow streams. For a perfect gas assumption the changes in entropy are then readily obtainable from:

$$
\Delta s=c_{p} \ln \frac{T_{2}}{T_{1}}-R \ln \frac{p_{2}}{p_{1}}
$$

Determining the changes in temperature and pressure from the transfer of heat is a standard problem in gas dynamics [11]. The equations for the temperature and pressure ratios are given in the Appendix.

Equations (2) and (3) above are now applied to illustrate some characteristics of intercooling thermodynamics when integrated into aero engines. The arguments are established using data from the optimal geared intercooled engine presented in [7]. This engine is an intercooled turbofan with a take-off fan pressure ratio (FPR) of 1.45, a take-off bypass ratio of 17.1 (BPR), operating in cruise at 35000 feet, ISA conditions and a flight Mach number of 0.81 is considered. A fixed amount of transferred heat is assumed based on a core temperature drop of $58 \mathrm{~K}$ in cruise, referring to the internal flow side of the intercooler. The stagnation pressure loss is computed in [7].

The exergy destruction variation with intermediate pressure (IP) compressor pressure ratio is shown in Figure 3. Line A represents the minimum IP compressor pressure ratio for which heat transfer is possible. At a lower value the inner bypass stream would heat up to a value higher than the IP exit temperature. Line $\mathrm{B}$ represents a maximum based on ideal cycle analysis for the engine presented in [7], i.e. the square root of the overall pressure ratio (OPR). D represents the optimal point for the geared IC engine presented in [7] and the curve $\mathrm{E}$ is the optimal point for the ultra-high OPR engine given in the same paper. $\mathrm{C}$ is the IP pressure ratio obtained for the intercooled cycle presented in [7] but the optimal pressure ratio is established based on the split ratio exponent (0.38) proposed in [4]. 


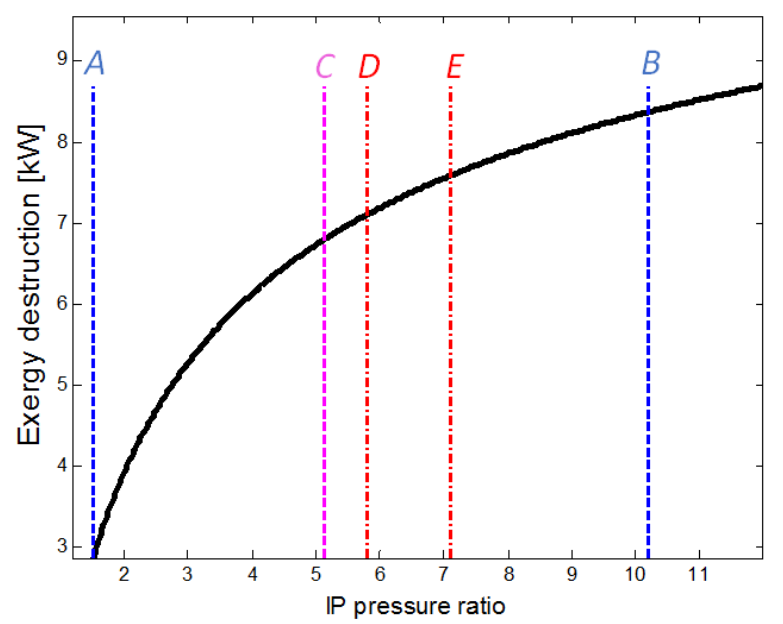

FIGURE 3: EXERGY DESTRUCTION AS A FUNCTION OF IP PRESSURE RATIO.

As seen in Figure 3, the irreversibility rate of intercooling is increased as the installation pressure is being increased. This is due to the temperature difference increase between the hot and cold fluids as shown from equation (2) and equation (3). This limits the benefits that can be achieved by intercooling in ultrahigh overall pressure ratio cycles. In such engines the optimal point of installation is shifted towards higher OPR's, which is illustrated by the change from D (high OPR cycle) to E (ultrahigh OPR cycle) in Figure 3.

However, as the temperature for heat rejection $T_{H}$ increases a secondary cycle extracting heat from the core would improve its benefits according to the general trends expressed by:

$$
\eta=K\left(1-\frac{T_{L}}{T_{H}}\right)
$$

Hence a Type 2 concept would potentially allow for a fundamentally better trend in efficiency than the one provided by pure intercooling concepts. As pressure ratios in turbofan engines increase, the efficiency of a bottoming cycle operating on the rejected heat from the intercooler would potentially increase.

Using heat rejected through intercooling to generate useful power is a novel approach that has not been studied in the past. The basic schematic of the system is illustrated in Figure 4. The intercooler would act as a boiler in a secondary fluid system. The heated fluid would then be used in a turbine to generate useful output. After the turbine the fluid would need to be condensed. A possible installation is to locate the condenser in the nacelle. The fluid is then pumped back again into the boiler. Since the amount of heat rejected from an intercooler is relatively large such a system should either transfer a large amount of work back to the shaft to reduce the fuel burn or generate additional thrust as part of a secondary engine installation.

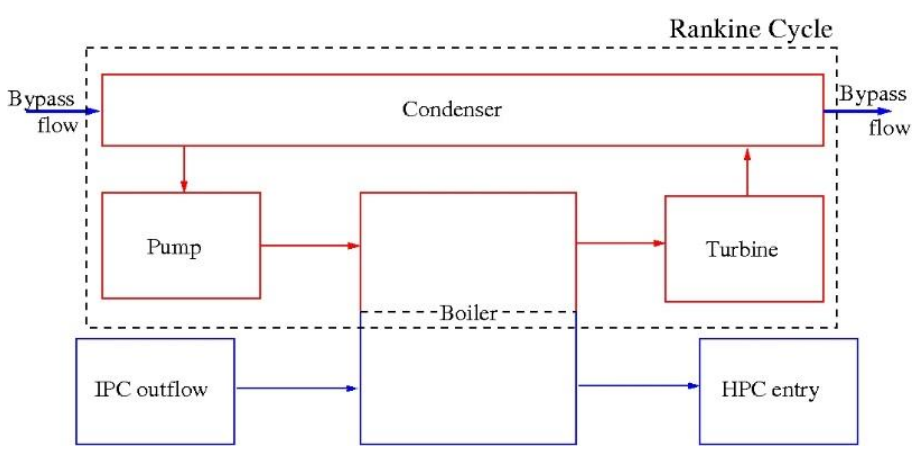

FIGURE 4: BASIC CONCEPT FOR RECOVERY OF REJECTED INTERCOOLER HEAT.

\section{A note on efficiency of heat rejection in intercoolers}

It should be noted that intercoolers, when fitted in the bypass flow, do provide a direct efficiency increase from the heat rejection. By increasing the speed of sound in the nozzle an increased thrust is obtained. Thereby the rejected heat is already working to establish an increase in the useful power to the aircraft. However, this process is very inefficient and is nowhere near the potential benefit that a secondary system could provide. For the case D presented in Figure 3 the efficiency for this process is estimated at $0.9 \%$. The efficiency is defined as the ratio of the useful power to the heat transferred in the intercooler. The useful power is obtained from the net thrust multiplied by flight speed. Despite this low efficiency intercooler fuel burn benefits are in the range $3-5 \%$ [7].

\section{TYPE 1 CONCEPTS}

In most of the aero engine intercooling concepts, the bypass flow has been considered as the main heat sink since the extraction of cooling air from the bypass duct can be performed in a relatively easy way. However, the use of the bypass flow as cooling air has two main drawbacks. Firstly, an air-to-air heat exchanger inherently leads to a bulky size, which will increase the engine weight and drag in the bypass flow nozzle, and secondly, the heat rejected from the core to the bypass flow has a negligible contribution for thrust, as mentioned in the previous section. In this section two different, but possibly complementary intercooling concepts are addressed. The first is the usage of the nacelle wetted surface as a replacement for the conventional intercooler heat exchanger surface during cruise operation. Thereafter, a fuel cooled intercooler configuration is analyzed and an efficiency estimation in terms of fuel burn reduction is given.

\section{Nacelle heat rejection}

As mentioned above the inclusion of a secondary nozzle for air-to-air heat exchange in the bypass duct may result in a prohibitive increase in drag, which could deny the benefits of intercooling in fuel burn reduction. Such a conflict can be resolved if another, already available, suitable surface is selected 

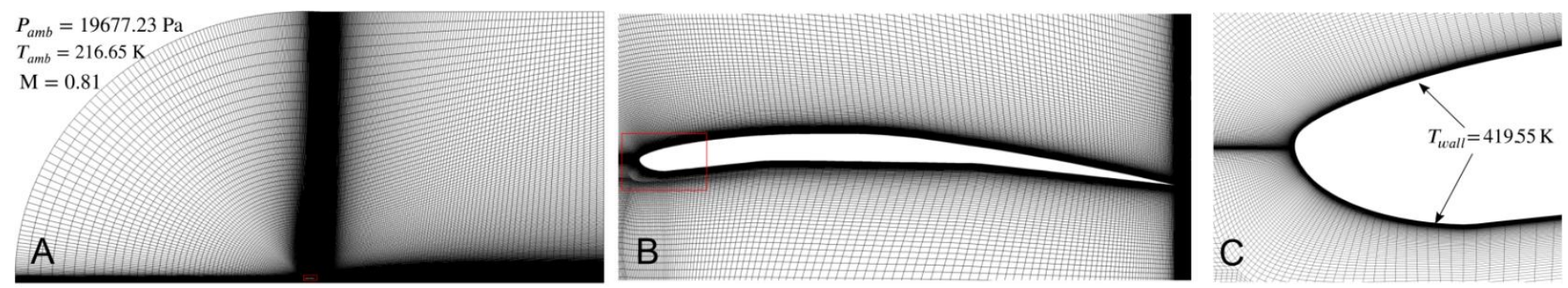

\section{FIGURE 5: NUMERICAL GRID USED FOR THE COMPUTATION OF THE NACELLE FLOW AND HEAT EXCHANGE; A: OVERALL VIEW; DETAILED VIEW OF THE NACELLE (B) AND LEADING EDGE (C).}

for core flow heat rejection. In this sub-section the feasibility of using the nacelle wetted surface to act as a heat exchanger during cruise conditions is analyzed using CFD tools. A twodimensional axisymmetric model is therefore created and the turbulent flow is computed for the cruise flight conditions of a 2025 optimized geared IC engine [7].

The commercial CFD code ANSYS Fluent 16 was used for all the computations in this section. For solving the twodimensional axisymmetric compressible flow RANS equations the pressure-based coupled solver was employed together with the $\mathrm{k}-\omega \mathrm{SST}$ turbulence model, with a $1 \%$ turbulence intensity at the boundary. Air is considered to be an ideal gas and viscosity is calculated as a function of temperature with Sutherland's three coefficient equation [12]. For variable interpolation the secondorder linear upwind scheme was adopted for the convection terms while the diffusive terms were approximated by centraldifferences. The two dimensional axisymmetric C-type mesh is illustrated in Figure 5. The grid is composed by 280,000 structured cells; the distance between the nacelle and the upstream and downstream boundaries is equal to 20 chords. The nacelle surface is covered by 468 points in the axial direction, while for the radial direction the first cell is located at a distance that ensures $y^{+}<1$. Between 20 to 30 cells are located in the boundary layer region, with a $10 \%$ growth rate, which allow for a full resolution of the viscous and temperature sub-layers. Regarding boundary conditions (BC), at the inlet and outlet a freestream $\mathrm{BC}$ is adopted for specifying the cruise flight conditions: $p_{a m b}=19677.23 \mathrm{~Pa} ; \quad T_{a m b}=216.65 \mathrm{~K} ; \mathrm{Ma}=$ 0.81 . At the solid walls a non-slip BC is imposed for velocity and a uniform wall temperature $T_{\text {wall }}=419.55 \mathrm{~K}$ is fixed, which is equal to the core flow temperature at the IPC exit. Therefore, it is assumed that the core flow temperature does not drop during its path in the intercooler. Moreover the temperature drop through the nacelle wall is neglected, which means that it performs as perfect thermal conductor. Both assumptions will overestimate the heat transfer flux (Figure 6) in the nacelle surface and therefore this case should be considered to be operating in ideal conditions. The nacelle was also tested without the fan and spinner, thus neglecting the swirl effect on the nacelle interior, which will inevitably modify the conditions in the bypass duct. It is however still not clear if the effects of such assumption are beneficial or prejudicial in terms of heat transfer rate. In the present study the authors are only concerned in exploring the feasibility of the concepts, and if a more stringent is required in the future to validate their viability.

An identical test case, with an adiabatic boundary condition at the nacelle wall, was computed for evaluating the effect of wall temperature in drag. A $10 \%$ reduction in nacelle drag was achieved for a wall temperature of $419.55 \mathrm{~K}$. Such reduction in drag is linked to a decrease of longitudinal momentum in the near wall region $[13,14,15]$, which results in a decrease of shear stress distribution on the nacelle wall as illustrated in Figure 7.

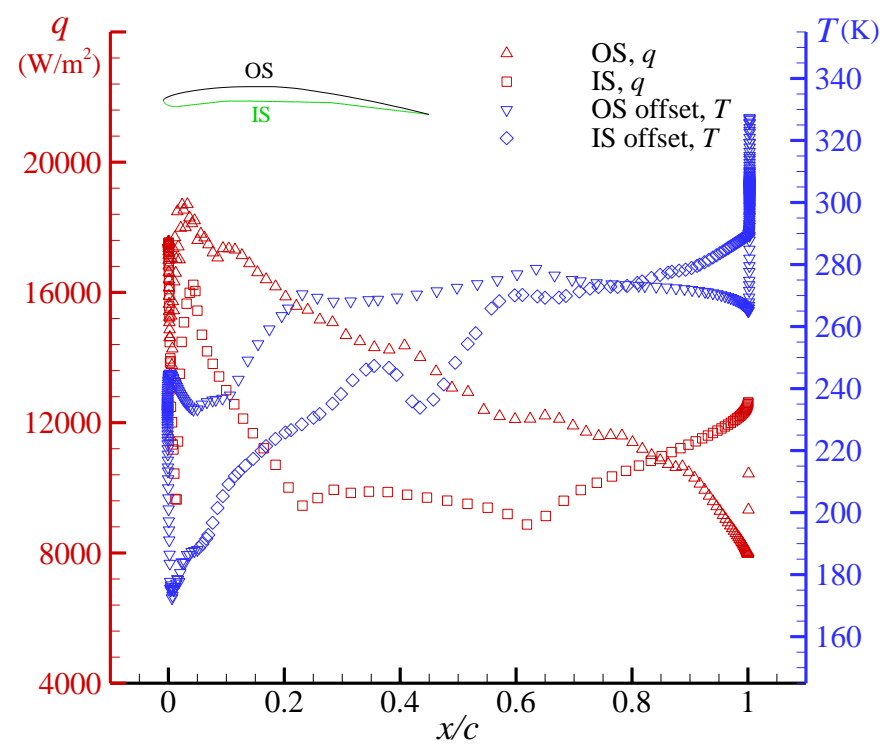

FIGURE 6: HEAT FLUX DISTRIBUTION ON THE NACELLE SURFACES. STATIC TEMPERATURE DISTRIBUTION AT AN OFFSET WALL DISTANCE OF 0.01 M.

However it should be emphasized that laminar to turbulent transition effects were not modeled. Which means that the effect of wall temperature in the occurrence of transition was not accounted for. It is expected that transition is triggered sooner when heat is transferred from the wall into the flow [17]. That being said one should expect that the $T_{\text {wall }}>T_{\infty}$ benefits in terms of drag reduction could be suppressed if laminar flow nacelles are selected for integration $[14,18]$. 


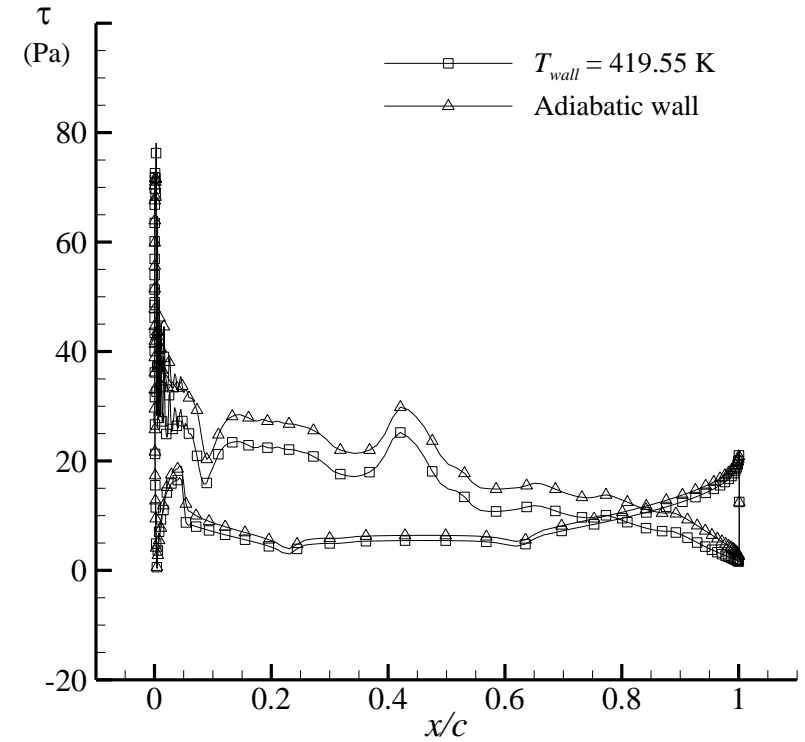

FIGURE 7: SHEAR-STRESS VARIATION IN THE NACELLE SURFACE FOR THE ADIABATIC AND FIXED TEMPERATURE WALL.

A second test case was devised for analyzing the feasibility of the concept in terms of reducing the core flow temperature. A two dimensional channel model was thus created in order to replicate the inner flow conditions of the nacelle heat exchanger, see Figure 8.

The length of the channel is equal to the curve length of the nacelle line $(L=11.45 \mathrm{~m})$ and its height is $h=0.05 \mathrm{~m}$, which gives us enough sectional area to accommodate the core mass flow rate during cruise $(\sim 20 \mathrm{~kg} / \mathrm{s})$ at a reasonable Mach number $(\mathrm{Ma}=0.12)$. The channel is composed by straight walls, hence any pressure losses that could be related to any type of bending are neglected, therefore this second case is also assumed to be operating under ideal conditions. The flow is considered turbulent with $1 \%$ turbulence intensity at the boundary and the $k-\omega$ SST model is once again employed. The inlet conditions in the channel are given by the IPC outlet conditions of the geared intercooled engine [7]. A uniform heat flux is specified in the top wall of the channel. The heat flux value is taken as the average of the nacelle heat flux previously computed, see Figure 6.

The results in Figure 8 show that at the outlet an average temperature of $356.37 \mathrm{~K}$ is achieved, which gives us a drop of $63 \mathrm{~K}$ of the initial core flow temperature. Such result clearly shows that the concept of nacelle heat exchanger could be feasible. However, a more detailed proof-of-concept model will be required for estimating a more realistic heat transfer rate. Still the concept of the nacelle heat rejection shows some inherent advantages over the classical approach of extracting cooling flow from the bypass duct. Because of the suppression of the pressure losses in the external side of the bypass air-to-air intercooler, $5 \%$ of the total for an engine with an OPR of 79, the possible gain for this technology could be up to $1 \%$ in terms of fuel burn reduction [15]. Moreover the $10 \%$ reduction in nacelle

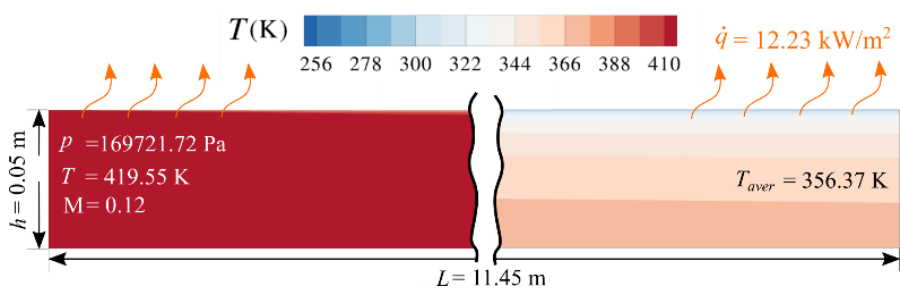

FIGURE 8: STATIC TEMPERATURE CONTOUR PLOT IN THE INLET AND OUTLET SECTIONS OF THE CHANNEL

drag would result in $0.6 \%$ reduction on the overall aircraft drag, which will translate into a $0.6 \%$ increase in specific range with similar impact in fuel burn reduction. However, it seems that the concept of nacelle heat rejection is only feasible during cruise conditions, where the air flow has enough momentum to cool down the nacelle surface. Therefore, it should be complemented by another system during take-off and TOC conditions, for example a fuel heat rejection intercooler.

\section{Fuel heat rejection}

The use of fuel as a heat sink has been investigated for many applications on heat management in an aircraft engine. Such solutions have been considered for cooling of turbine cooling air or electrical systems cooling where only a small amount of fuel flow would be required [20]. These installations assumed that the fuel was then directly used for combustion and not circulated back into the fuel tanks as proposed in [21]. An intercooled engine with the fuel as the coolant flow is now studied and the potential performance for this engine is discussed.

In previous aero engine intercooling studies [5, 7], it has been shown that the intercooling technology, as a trigger for a high OPR engine, is not required at cruise but critical for the take-off and climb phases. Hence, a strategy of using the fuel as the cooling flow is that the intercooling acts from take-off to topof-climb only. For a $6800 \mathrm{~km}$ mission, the duration will be 940 seconds and a full fuel tank could store $30000 \mathrm{~kg}$ of fuel. When all the fuel is considered as the heat sink, a $32 \mathrm{~kg} / \mathrm{s}$ cooling fuel flow could be obtained. For safety issue, it is important that when using the fuel as the coolant its temperature in the tank should stay below the fuel's auto-ignition temperature. To reduce such a risk, a fuel stabilization unit can be installed. This unit removes oxygen from the fuel stream by means of a membrane to limit high temperature coking in the burner fuel lines. The heat capacity of the fuel can thus be increased by up to $250 \mathrm{~K}$ [20].

Based on the estimates of the performance levels achievable for an engine entering into service around year 2025 as shown in Table 1, the temperature trend versus OPR for the IC inlet and outlet, HPC exit and fuel after intercooling is plotted in Figure 9. A value of 0.38 of the pressure ratio split component is used here as it is the optimal value estimated by Kyprianidis et al. [22] for an intercooled engine and also discussed by the authors [10]. To be able to keep the HPC exit flow temperature lower than the limit for turbine cooling consideration, it can be seen that intercooling is needed for the engine with OPR higher than 47.8. 
TABLE 1: DESIGN POINT PERFORMANCE PARAMETERS (TAKE-OFF).

\begin{tabular}{|l|c|}
\hline Parameter & Value \\
\hline$T_{\text {HPC,exit }}$ & $<950 \mathrm{~K}$ \\
\hline$T_{\text {Combustorexit }}$ & $<1900 \mathrm{~K}$ \\
\hline$T_{\text {blade }}$ & $<1210 \mathrm{~K}$ \\
\hline$\eta_{\text {fan }}$ & $93.5 \%$ \\
\hline$\eta_{I P C}$ & $92.2 \%$ \\
\hline$\eta_{\text {HPC }}$ & $92.5 \%$ \\
\hline FPR (inner) & 1.31 \\
\hline Pressure ratio split component & 0.38 \\
\hline Net Thrust & $65625 \mathrm{lbf}$ \\
\hline
\end{tabular}

For the OPR up to 140, ideally the heat capacity of the fuel is more than sufficient for accommodating the heat rejected from the core flow. It can be seen however in Figure 9 that for an OPR higher than 120, the fuel temperature after intercooling is getting very close to the auto-ignition temperature of jet A fuel $\left(211^{\circ} \mathrm{C}\right.$, $484 \mathrm{~K}$ ). Technology such as the fuel stabilization unit [20] would therefore help to reach such high OPR in a safe manner. Accordingly, the heat exchanger effectiveness required versus OPR is plotted in Figure 10. The two-pass tubular intercooler concept designed and developed by Zhao and Grönstedt [23] is considered in the present work as an example. According to Kays and Londons [24], who compute the heat transfer effectiveness against the number of transfer units (NTU), the effectiveness of such an intercooler concept is achievable. Fuel has much higher density and twice the specific heat capacity than the air. Therefore, for the same NTU, the fuel heat exchanger will be much smaller. Hence, the intercooled engine with a fuel heat sink could result in a smaller engine core.

In addition, the heat transferred to the fuel has a positive effect on the fuel consumption as preheat. This effect is estimated to reduce fuel burn by $0.3 \%$ when compared to the air-to-air geared intercooled aero engine described in [5]. Last but not least, without extracting the bypass air through the intercooler, the bypass flow pressure loss reported in [5] is reduced substantially. Based on the exchange rate established in [19] a $1 \%$ pressure loss in the external side of the intercooler reflects as a $0.2 \%$ increase in fuel burn. The elimination of the large loss through the external side of the intercooler can lead to a $1 \%$ fuel burn reduction compared to the air-to-air intercooled geared aero engine reported in [5]. In total, intercooling using fuel as the coolant flow could benefit up to $1.3 \%$ fuel burn reduction compared to a conventional air-to-air intercooling.

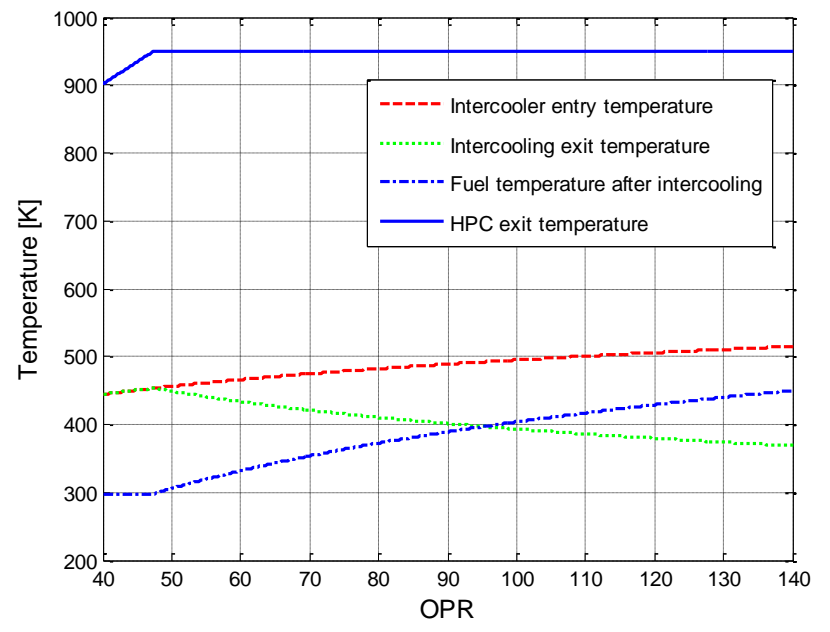

FIGURE 9: TEMPERATURE TREND WITH VARYING OPR (INTERCOOLING FOR T/O AND CLIMB PHASES ONLY).

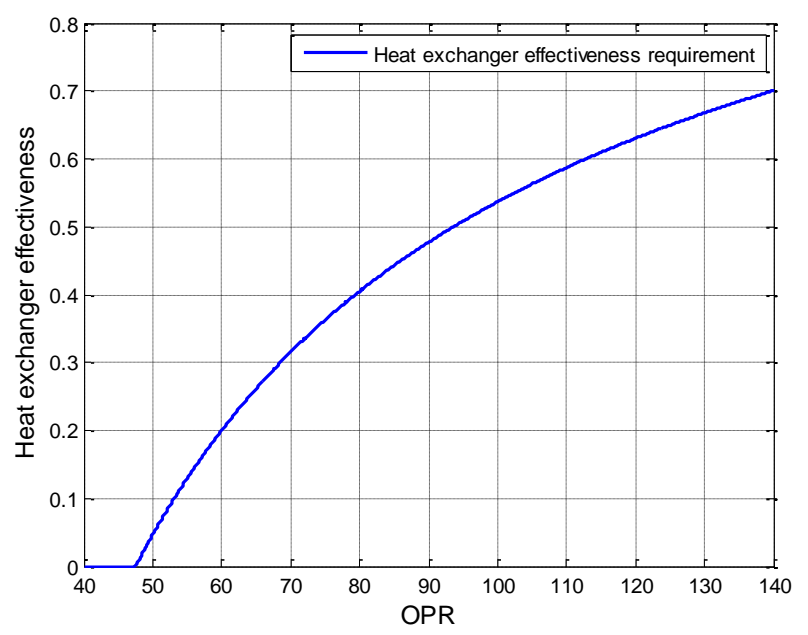

FIGURE 10: HEAT EXCHANGER EFFECTIVENESS.

\section{TYPE 2 CONCEPTS: USEFUL POWER FROM HEAT REJECTION}

To estimate the potential power that could be generated from a cycle recovering intercooling heat the use of equation (4) is proposed. For convenience it is repeated here:

$$
\eta=K\left(1-\frac{T_{L}}{T_{H}}\right)
$$

The constant $K$ is dependent on the design of the secondary system which in turn depends on a number of detailed design parameters. The temperatures in the Carnot factor are to be understood as heat averaged temperatures. Defining $T_{L}$ is relatively straightforward, since either the bypass channel or nacelle external temperature will be used as a heat sink 


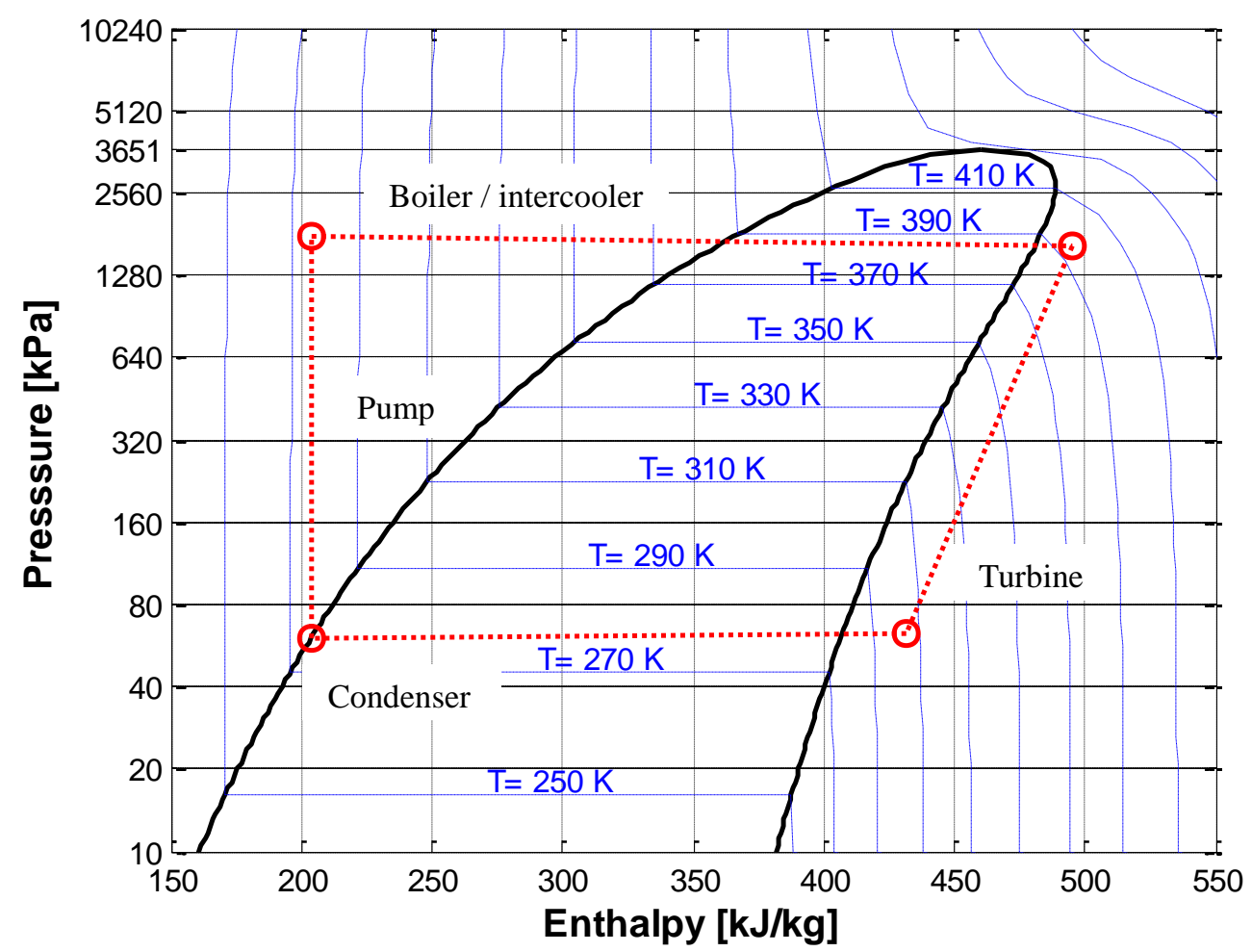

FIGURE 11: SECONDARY RANKINE CYCLE OPERATING CONDITIONS (CASE 4) FOR R245FA FLUID. PUMP ENTRY (POINT 1), ENTRY TO HEAT RECOVERY HEAT EXCHANGER (POINT 2), TURBINE ENTRY (POINT 3) AND CONDENSER ENTRY (POINT 4).

Both the nacelle external temperature and the bypass temperature are available from performance calculations. The value on $T_{L}$ will then be established as the readily available temperature of the heat sink plus a necessary temperature difference to create a sufficiently compact heat exchanger. $T_{H}$ is depending on intercooler installation and foremost on the high speed booster exit temperature.

To estimate a realistic performance potential of a heat recovery system the constant $\mathrm{K}$ in equation (4) is initially obtained from previous research work. Correlating $\mathrm{K}$ from a set of fluids representative for the temperature range of the installation, based on the work by Brasz and Bilbow [25], a value of 0.65 is established.

Four cases of a Type 2 installation are now explored for the cruise flight conditions with respect to their performance potential, and compared to the reference geared intercooled engine concept reported in [7]. The four different cases and the baseline are presented below.

- Reference case. The reference case is the year 2025 advanced geared intercooled engine concept reported in [7], at cruise point. The cycle runs with the variable intercooler exhaust nozzle (see Figure 1) in closed position to minimize irreversibility and reduce heat rejection in cruise.

- Case 1. Case 1 is based on the Reference case but the heat rejected in the intercooler is now used by a secondary heat recovery system as illustrated in Figure 4. For Case 1, the secondary heat recovery system is not detailed further but its efficiency is estimated using equation (4) (setting K to 0.65). Note that the Case 1 definition constitutes the cycle optimum established in [7]. Since the heat removal does not influence the optimum cycle point, the rejected heat will generate additional useful power that immediately will reduce the $\mathrm{SFC}$.

- Case 2. Case 2 is similar to Case 1, but the useful power generated by the secondary heat recovery system is increased by increasing the heat rejection from the intercooler. Increasing the heat rejection may be beneficial, now that a part of the rejected heat is transformed into additional useful power rather than to marginally increase the thrust through an auxiliary nozzle. However, when extracting more heat the underlying intercooler cycle optimum is now influenced, and the cycle point moves away from its optimal point. It is thus unclear whether this will improve the performance and calculations are needed to predict the SFC influence. To estimate a realistic amount of heat rejection that could be achieved through the intercooler, the Reference case is used but with an open auxiliary nozzle. This will predict a feasible increase in heat transfer, as well as the associated increase in pressure loss. It is likely that a heat exchanger cooled by a liquid secondary cycle fluid could reject even more heat and 
accomplish this heat rejection with a lower pressure loss than accomplished by air cooling, making this estimate conservative.

- Case 3. Case 3 is defined by performing a cycle optimization on Case 2. The increased heat transfer established in Case 2 changes the optimality of the underlying cycle. Case 3 is therefore defined by reoptimizing the Fan Pressure Ratio (FPR), Bypass Ratio (BPR) and Overall Pressure Ratio (OPR) for a variable intercooler exhaust nozzle fully open. It is thus clear that Case 3 should provide a reduced SFC in relation to Case 2.

- Case 4. Case 4 verifies the assumptions made in Case 3 by developing a thermodynamic definition for the Rankine cycle being used. This involves selecting a working fluid and providing turbomachinery efficiencies for the involved components.

Table 2 summarizes the results obtained for the different cases. Eta $(\eta)$ is the efficiency of the bottoming cycle. As explained, $\eta$ is calculated with Equation (4) for Case 1, Case 2 and Case 3. For Case 4 the efficiency is established from a set of Rankine cycle conceptual design data as given in Figure 11 and Table 3. $\Delta T_{\text {Core }}$ is the temperature reduction of the core flow generated by the intercooler. The heat rejected into the bottoming cycle now produces an additional useful power. To account for that the generated power will have to be translated into thrust, either by feeding it back to the engine shaft or by driving additional propulsors, $20 \%$ of the generated useful power is removed. This is consistent with a relatively conservative assumption on a propulsive efficiency.

\section{TABLE 2: INTERCOOLED ENGINE WITH RECOVERY OF HEAT REJECTION.}

\begin{tabular}{|l|c|c|c|c|c|}
\hline & $\begin{array}{l}\text { Reference } \\
\text { case }\end{array}$ & Case 1 & Case 2 & Case 3 & Case 4 \\
\hline BPR & 19.0 & 19.0 & 19.1 & 21.35 & 21.41 \\
\hline OPR & 74 & 74 & 74.6 & 87 & 87 \\
\hline FPR & 1.44 & 1.44 & 1.41 & 1.38 & 1.38 \\
\hline $\mathrm{T}_{\mathrm{H}}[\mathrm{K}]$ & 370 & 370 & 368 & 375 & 375 \\
\hline $\mathrm{Eta}$ & & 24.5 & 24.2 & 25 & 17.17 \\
\hline$\Delta \mathrm{T}_{\text {Core }}[\mathrm{K}]$ & 58.51 & 58.51 & 72.77 & 72.77 & 72.77 \\
\hline $\begin{array}{l}\text { Useful } \\
\text { power } \\
{[\mathrm{kW}]}\end{array}$ & $\mathrm{NA}$ & 280 & 357 & 370 & 254 \\
\hline $\begin{array}{l}\mathrm{SFC} \\
\text { (mg/Ns) }\end{array}$ & 12.76 & 12.5 & 12.48 & 12.28 & 12.4 \\
\hline $\begin{array}{l}\text { SFC } \\
\text { reduction }\end{array}$ & NA & $2.03 \%$ & $2.19 \%$ & $3.76 \%$ & $2.9 \%$ \\
\hline
\end{tabular}

The fluid selected is R245FA. The operating conditions for the heat recovery Rankine cycle is illustrated in Figure 11 and detailed in Table 3. The fluid R245FA was a preferred choice over two other options, namely R134A and R410A. These fluids have condensing and boiling pressures that are less suitable for the operational temperatures considered here. The condenser exit pressure used for the R245FA installation was around $60 \mathrm{kPa}$. This should allow for a relatively light installation considering that the ambient pressure is around $20 \mathrm{kPa}$ in cruise and around a 1 bar at take-off. The boiler pressure is designed for around $1200 \mathrm{kPa}$ comparing to the intercooler internal pressure of around $200 \mathrm{kPa}$.

The fact that the boiler can be designed with a hot pressure substantially higher than ambient gives intercooler Rankine installations an advantage over recuperated installations. Recuperated solutions, i.e. installations using heat from the core exhaust, would have to work with a hot pressure close to the exhaust pressure from the low pressure turbine.

TABLE 3: RANKINE CYCLE DETAILS SUPPLEMENTING THE CHART PRESENTED IN FIGURE 11.

\begin{tabular}{|l|c|c|}
\cline { 2 - 3 } \multicolumn{1}{c|}{} & $\begin{array}{l}\text { Pressure } \\
{[\mathrm{kPa}]}\end{array}$ & $\begin{array}{l}\text { Enthalpy } \\
{[\mathrm{kJ} / \mathrm{kg}]}\end{array}$ \\
\hline Point 1 & 60 & 203.6 \\
\hline Point 2 & 1306 & 204.1 \\
\hline Point 3 & 1210 & 486 \\
\hline Point 4 & 63.2 & 429 \\
\hline Turbine and pump efficiencies & $85 \%$ & \multicolumn{2}{|c}{} \\
\cline { 1 - 2 } & \multicolumn{2}{|c}{}
\end{tabular}

The use of the bottoming cycle produces SFC savings, between 2 to $3.76 \%$. The results show that by fully opening the variable nozzle, the useful power is increased and the SFC improvement is greater. The $-2.9 \%$ SFC reduction of Case 4 takes the effects of irreversibility in the secondary cycle into account. Internal flow losses through the boiler are also accounted for by being consistent with the losses predicted in [7]. What is not accounted for is condenser, pump, turbine and ducting system weights and additional installation losses due to possible increase in engine drag. The boiler and condenser weights will depend on pressure difference between the secondary fluid and the external pressure. The pressures noted for the R245FA fluid indicate that installations with moderate weight increase are possible. It should be noted that the additional losses from such installations are expected to be lower than the gains predicted here. Even a $1500 \mathrm{~kg}$ weight addition is expected to increase fuel burn by the order of $2 \%$. The drag added by the entire nacelle is estimated at $1.5 \%$ SFC. Results on the Type 1 concepts and nacelle cooling indicate that the penalty for heat rejection could be designed out with a modest drag penalty.

\section{DISCUSSION AND CONCLUSIONS}

Previous work on intercooling has demonstrated a fuel burn saving potential in the range of $4.5-5.3 \%$, depending on primarily the overall pressure ratio [7]. These benefits have been shown to originate primarily from enabling higher overall pressure ratio cycles as well as reducing cooling flow need. To advance the potential of intercooling further, two routes of innovation are possible: 1) exploring synergies by using already 
wetted surface to establish the heat rejection and 2) finding more efficient use of the rejected heat.

A first analysis of the nacelle heat rejection concept has provided some useful insight and demonstrated that a potential $1.6 \%$ fuel burn reduction could be obtained from this concept. Initially, it may be thought that the external surface would not be sufficient for the cooling need. However, having an intercooler concept that is designed primarily to enable an increased overall pressure ratio and a reduced turbine cooling flow need [7], makes the installation substantially more compact than if a design maximizing heat transfer is sought. In addition, ever increasing bypass ratio trends reduces the relative volume that the core flow will occupy. It has been shown feasible to reject the necessary amount of heat needed for cruise operation of the intercooler using only the wet surface of the nacelle. In association with this it was also explained that the heat addition actually contributes to a net reduction in drag. The reduction is, however, achieved by decreasing the near wall region longitudinal momentum, which will destabilize the boundary layer. In cruise this is expected to impose no restrictions on the operation but at critical aerodynamic design cases for the nacelle, a reduced aerodynamic stability is to be expected. However, such drawbacks can of course be alleviated by making the nacelle aerodynamic design less aggressive. Alternatively, as studied in this work, the nacelle cooling may only be operated in cruise.

Another and more attractive way to reject heat, since the heat rejected is actually re-used, is to heat the fuel. The most straightforward way to implement such a system would be to heat the fuel on its way to the engine. However, in case of an intercooler the amount of heat that needs to be rejected is quite substantial, necessitating a fuel re-circulating system. The proposed solutions has shown to provide clearly acceptable fuel temperature increases while being operable from take-off up to cruise altitude. This is necessary to make such a system operable since a substantial variation in initial fuel temperature will be present when integrated into airline operation. Preliminary results show that a $1.3 \%$ fuel burn reduction could potentially be obtained with this technology.

As illustrated analytically a drawback with intercooling is that irreversibility in the intercooler increases as heat is rejected at higher temperature. This is driven by the ratio of the core flow temperature and the bypass temperature. Since the intercooler primarily derives its benefits from enabling higher overall pressure ratio, and optimal installation pressure increases with pressure ratio, this trend is unfavorable. However, the second type of intercooler concept considered in this work, Type 2 concepts, shows an opposing trend, removing the unfavorable pressure ratio dependence of intercooler heat transfer. This is because the theoretical efficiency of a bottoming cycle increases with the hot temperature. The dominating effect with respect to intercooling inefficiency is however that heat is rejected to the surrounding providing virtually no benefit in terms of thrust. The efficiency established for the conversion of rejected heat to increased thrust was estimated to be below $1 \%$. The proposed secondary cycle, allowing to generate useful power at close to $17 \%$ efficiency, increases the efficiency of an intercooled engine dramatically. As discussed, the close to $3 \%$ SFC benefit, beyond what can be achieved by an intercooled geared engine concept, was estimated as an upper bound. The level of improvement is large, but further studies need to be pursued to analyze the benefit also when the losses are taken fully into account.

\section{ACKNOWLEDGEMENT}

The author would like to thank the European Commission for supporting the development of engine technologies in the past 15 years. A large part of this study has been carried out in the framework of the ENOVAL program (Engine Module Validator), which receives funding from the European Commission's Seventh Framework Program [FP7/2007-2013] under the Grant Agreement No. 604999.

\section{REFERENCES}

[1] E. comission, "Flightpath 2050 - Europe's Vision for Aviation," Luxembourg, 2011.

[2] ENOVAL Proposal Part B, 2012.

[3] P. W. Kwan, D. R. H. Gillepsie, R. D. Stieger and A. M. Rolt, "Minimising Loss in a Heat Exchanger Installation for an Intercooled Turbofan Engine," in Proceedings of the ASME Turbo Expo 2011, 2011.

[4] K. G. Kyprianidis, A. M. Rolt and T. Grönstedt, "Multidisciplinary Analysis of a Geared Fan Intercooled Core Aero-Engine," Journal of Engineering for Gas Turbines and Power, vol. 136, no. 1, January 2014.

[5] X. Zhao, T. Grönstedt and K. G. Kyprianidis, "Assessment of the performance potential for a two-pass cross flow intercooler for aero engine applications," in International Society for Airbreathing Engines, ISABE, Busan, South Korea, 2013.

[6] C. A. Barrow, J. F. Carotte, A. D. Walker and A. M. Rolt, "Aerodynamic Performance of a Coolant Flow Off-Take Downstream of an OGV," in ASME 2011 Turbo Expo: Turbine Technical Conference and Exposition, Vancouver, British Columbia, Canada, 2011.

[7] X. Zhao, O. Thulin and T. Grönstedt, "First and Second Law Analysis of Intercooled Turbofan Engine," J. Eng. Gas Turbines Power, vol. 138, no. 2, 2015.

[8] X. Zhao and T. Grönstedt, "Aero-engine intercooling optimization using a variable flow path," in International Society for Airbreathing Engines, ISABE, Phoenix, USA, 2015.

[9] A. Perullo, D. N. Mavris and E. Fonseca, "An integrated assessment of an organic Rankine cycle concept for use in onboard aircraft power generation," in ASME Turbo Expo 2013: Turbine Technical Conference and Exposition, San Antonio, Texas, USA, 2013.

[10] T. Grönstedt, M. Irannezhad, L. Xu, O. Thulin and A. Lundbladh, "First and Second Law Analysis of Future Aircraft Engines," vol. 136, no. 3, 2014. 
[11] J. D. Anderson, Modern compressible flow: with historical perspective, McGraw Hill Higher Education, 1990.

[12] ANSYS Inc., Fluent Theory Guide, 2013.

[13] D. M. Bushnell, "Aircraft Drag Reduction-A Review," Journal of Aerospace Engineering, vol. 217, nr 1, pp. 118, 2003.

[14] B. R. Kramer, B. C. Smith, J. P. Heid, G. K. Noffz, D. M. Richwine and T. Ng, "Drag Reduction Experiments Using Boundary Layer Heating," in 37th AIAA Aerospace Sciences Meeting and Exhibit, Aerospace Sciences Meetings, Reno, NV, 1999.

[15] J. C. Lin and R. L. Ash, "Wall Temperature Control of Low-Speed Body Drag," Journal of Aircraft, vol. 23, no. 1, pp. 93-94, 1986.

[16] S. Özgen, "Effect of heat transfer on stability and transition characteristics of boundary-layers," International Journal of Heat and Mass Transfer, vol. 47, no. 22, p. 4697-4712, 2004.

[17] Y. Lin, T. Robinson, J. Early, D. Riordan, J. Tweedie and L. Magee, "Implementation of Menter's Transition Model on an Isolated Natural Laminar Flow Nacelle," AIAA Journal, vol. 49, no. 4, pp. 824-835, 2011.

[18] P. Meyer, "Laminar flow nacelle for an aircraft engine". Patent US7048230 B2, 23 May 2006.

[19] W. Camilleri, E. Anselmi, V. Sethi, P. Laskaridis, T. Grönstedt, X. Zhao, A. Rolt and P. Cobas, "Concept description and assessment of the main features of a geared intercooled reversed flow core engine," J. of Aerospace Engineering, vol. 229, no. 9, pp. 1631-1639, July 2015.

[20] A. Lundbladh, S. Donnerhack, S. Streinfinger, F. Giuliani and T. Grönstedt, "Future innovative cores for commercial engines," in International Symposium on Air Breathing Engines, ISABE, Montreal, Kanada, 2009.

[21] A. Rolt, "Engine". US Patent 7,7716,913, 18 May 2010.

[22] K. G. Kyprianidis and A. M. Rolt, "On the Optimization of a Geared Fan Intercooled Core Engine Design," J. Eng. Gas Turbines Power, vol. 137, no. 4, 28 October 2014.

[23] X. Zhao and T. Grönstedt, "Conceptual design of a twopass cross-flow aeroengine intercooler," J. of Aerospace Engineering, vol. 229, no. 11, pp. 2006-2023, 19 September 2015.

[24] W. M. Kays and A. L. London, Compact heat exchangers, second ed., New York: McGraw-Hill, 1964.

[25] L. J. Brasz and W. M. Bilbow, "Ranking of Working Fuids for Organic Rankine Cycle Applications," in International Refrigeration and Air Conditioning Conference, Purdue Univerity, USA, 2004.

\section{APPENDIX}

\section{Heat addition}

The addition of an amount of heat $\mathrm{q}$ leads to a change in stagnation temperature $\Delta \mathrm{T} 0$ according to:

$$
q=c_{p}\left(T_{02}-T_{01}\right)
$$

The Mach number will then change according to [11]:

$$
\frac{T_{02}}{T_{01}}=\left(\frac{1+\gamma M_{1}^{2}}{1+\gamma M_{2}^{2}}\right)^{2}\left(\frac{M_{2}^{2}}{M_{1}^{2}}\right)^{2}\left(\frac{1+\frac{\gamma-1}{2} M_{2}^{2}}{1+\frac{\gamma-1}{2} M_{1}^{2}}\right)
$$

For a known stagnation temperature change the outflow Mach number, M2, is then readily computed from an iteration. Having M2 immediately produces the pressure and temperature through:

$$
\frac{p_{02}}{p_{01}}=\frac{1+\gamma M_{1}^{2}}{1+\gamma M_{2}^{2}}\left(\frac{1+\frac{\gamma-1}{2} M_{2}^{2}}{1+\frac{\gamma-1}{2} M_{1}^{2}}\right)^{\frac{\gamma}{\gamma-1}}
$$

